\title{
Testing of an Indoor Air Cleaner for Particulate Pollutants under Realistic Conditions in an Office Room
}

\author{
Miriam Küpper, Christof Asbach*, Ute Schneiderwind, Hartmut Finger, \\ Daniel Spiegelhoff, Stefan Schumacher
}

\author{
Institute of Energy and Environmental Technology e.V. (IUTA), 47229 Duisburg, Germany
}

\begin{abstract}
Mobile air cleaners have been gaining popularity as potentially effective tools for improving indoor air quality. Usually, the efficacy of an air cleaner is quantified by determination of the clean air delivery rate (CADR) under strictly defined conditions within test chambers lacking furniture and featuring adequate and homogeneous mixing of the test aerosol. By contrast, real-world scenarios may considerably differ from these conditions, resulting in adverse consequences, as a less homogeneous distribution of the cleaned air may produce spatial differences in the CADR and lead to lower overall efficacy for the air cleaner.

Therefore, in this study, the spatial variance of a mobile air purifier's cleaning efficacy across several positions in a furnished and in-use office room was investigated for four different scenarios, in each of which the air cleaner was placed in a different position inside the room. Ambient outdoor air was supplied as target aerosol by opening a window prior to the measurements, and the local CADR was calculated based on the decay rate of the lung-deposited surface area (LDSA) concentration. It was found that the relative decay of the LDSA concentration was almost identical for all of the measuring points throughout the room, hinting at a homogeneous distribution of the cleaned air. Varying the position of the air cleaner in the room resulted in only minor differences, except when the device was placed in an intentionally unfavourable location under a desk, which significantly reduced the cleaning efficacy. Despite the high spatial homogeneity, the CADR in the office room was significantly lower than the one determined according to the Chinese standard GB/T 18801-2015 in a standardized test chamber, which is presumably mainly attributable to the differing size distributions of the realistic and the standard test aerosol.
\end{abstract}

Keywords: Indoor air quality; Mobile air cleaners; Spatial variance of CADR; Ultrafine particles; Lung deposited surface area concentration.

\section{INTRODUCTION}

\section{Rising Importance of Air Cleaning Devices}

Negative health effects of particulate matter (PM) have been shown by numerous epidemiologic and toxicological studies (e.g., Dockery et al., 1993; Anderson et al., 2012). In urban parts of industrialized countries people spend most of their time indoors, including residential and occupational environments as well as means of transportation. Consequently, indoor aerosols are highly relevant for public health (Jenkins et al., 1992; Leech et al., 2002). In addition to severe health effects, impacts of PM pollution on indoor worker productivity in the manufacturing sector

\footnotetext{
* Corresponding author.

Tel.: +49 (0) 2065/418-409; Fax: +49 (0) 2065 418-211

E-mail address: asbach@iuta.de
}

and even minor impairments of respiratory and cardiovascular function were shown to be capable of increasing fatigue, decreasing focus, and impairing cognition in a recent review by Zivin and Neidell (2018). Apart from indoor sources contributing to indoor air pollution, infiltration processes can play an important role-especially if ambient air quality is poor.

In general, two types of air cleaning devices can be used to reduce indoor air pollution: static heating, ventilation, and air conditioning (HVAC) systems or portable air cleaners. Besides their sheer size, the main difference between the approaches is that HVAC systems use single pass filtration, i.e., air from outside is filtered by an in-duct filter and released into the room to replace the polluted room air, whereas indoor air cleaners suck the air from the room and draw it through a filter before the cleaned air is released back into the room. Indoor air cleaners consequently recirculate the air in the room. Although it has been shown by several studies during the past years that in-duct filters 
are typically more effective than stand-alone units (e.g., Sublett, 2011, and references therein; Hanley et al., 1994; Batterman et al., 2005; Polidori et al., 2013), a recent study by Noh and Yook (2016) revealed the performance of modern stand-alone devices to exceed that of an in-duct ventilation system run with identical airflow rate and even identified a higher cost-effectiveness for portable air cleaners for small rooms. Moreover, aside from effectivity issues one has to take account of the fact that many flats and private houses are not equipped with HVAC systems and therefore portable stand-alone air cleaning devices provide the only possible solution for reducing indoor air pollution. The coincidence of the use of portable air cleaners with several positive health effects has already been proven by various studies. For instance, Zuraimi et al. (2011) identified a mitigation of influenza infection risks via the airborne route for a caregiver or a spouse sharing a room with an infected person and the improvement of symptoms and quality of life of children suffering from perennial allergic rhinitis was shown by another study applying air cleaners (Huang, 1993). Additionally, significant improvements of several biological markers in the blood of young and healthy subjects were identified as a consequence of air cleaner usage (Chen et al., 2015). It should, however, also be noted that a portable air cleaner does not exchange the air and therefore gaseous pollutants that are not filtered out such as $\mathrm{CO}_{2}$ may accumulate in the air in the same way as if no means for air cleaning were used.

\section{Types and Efficiency of Portable Air Cleaners}

Different methods can be applied for air purification. Whilst chemical reactions, such as photocatalytic, plasma or biological oxidation, are appropriate for the reduction of volatile organic compounds (VOCs) (Guieysse et al., 2008; Mo et al., 2009; Schmid et al., 2010), particulate air pollution can be decreased more efficiently by devices based on different kinds of filters. In terms of ultrafine particle (UFP) removal rate, those devices applying highly-efficient fibrous filters presently seem to be the most efficient air cleaners on the market (e.g., Ward et al., 2005; Sultan et al., 2011; Ma et al., 2016).

To quantify the cleaning efficacy of portable air cleaners, the clean air delivery rate (CADR) is mostly used as a universal metric (e.g., Nelson et al., 1993). It describes the flow rate of clean air delivered to the room by the air cleaner and thus ideally equals the product of the particle removal efficiency of the device $\eta_{p}$ and the volumetric flow rate $\dot{V}$ drawn through the device:

$$
C A D R=\eta_{p} \dot{V}
$$

Since the flow rate of an indoor air cleaner is usually not easily accessible, a different approach is taken to determine the CADR. Measurement specifications are for example defined in the Chinese standard GB/T 188012015, according to which two particle concentration decay rates have to be determined within a test chamber with a defined volume $\left(V_{\text {chamber }}\right)$ : a natural decay rate with inactive air cleaner $\left(k_{\text {nat }}\right)$ and a decay rate detected under usage of the indoor air cleaner $\left(k_{A C}\right)$. The decay rates $k$ are determined from the measured temporal decay of the particle concentration $C(t)$, starting from the initial concentration $C_{0}$ :

$C(t)=C_{0} e^{-k \cdot t}$

Knowing these experimental parameters, CADR can be calculated according to the following formula:

$C A D R=\left(k_{A C}-k_{\text {nat }}\right) V_{\text {chamber }}$

The measurements are carried out in a $30 \mathrm{~m}^{3}$ chamber, which is empty except for the air cleaner placed on a table, two fans to mix and recirculate the air and some measurement periphery (mainly tubing). The chamber is kept at a temperature of $25 \pm 2{ }^{\circ} \mathrm{C}$ and a relative humidity of $50 \pm 10 \%$. Cigarette smoke is used as test aerosol and the number concentration of particles $>0.3 \mu \mathrm{m}$ is measured using an optical aerosol spectrometer. Although the spectrometer measures particle size distributions, only size-integrated number concentrations are used for the determination of CADR according to the standard. It should be noted that the particle removal characteristics of the filters used are particle size dependent, and consequently the CADR depends on the particle size distribution of the target aerosol.

The standardized test parameters might not be applicable to typical applications of air cleaners, e.g., due to different ventilation, air flow, PM sources and size distribution characteristics, as well as higher deposition rates due to furniture (e.g., Fisk et al., 2002; Batterman et al., 2005). Possible spatial inhomogeneity in the distribution of the cleaned air under real use of the air cleaners may have significant impacts on exposure, since the cleaning efficacy might be significantly lower within the breathing zone of a person than suggested by CADR values determined in a test chamber. So far, the number of published studies on efficacy of air cleaners in real and even inhabited flats or houses is limited (e.g., Batterman et al., 2005; Barn et al., 2008; Bräuner et al., 2008; Ma et al., 2016). None of these studies investigated possible spatial differences in air quality in a room, whilst recent studies by Chen et al. (2017) and Jin et al. (2016) dealing with this topic are based on models and simulations validated by test chamber experiments. Thus, to the best of our knowledge, the present study is the first one investigating possible spatial variation in efficacy of an indoor air cleaner under real conditions.

Additionally, instead of the particle number concentration in the size range from 0.3 to $10 \mu \mathrm{m}$ as defined by Chinese standard GB/T 18801-2015, in the present study we use the lung-deposited surface area (LDSA) concentration as a metric. The LDSA concentration describes the fraction of the airborne surface area concentration that would deposit upon inhalation in the alveolar region of the human lung. Surface area has been reported to be a better predictor of adverse health outcomes than mass or number concentration (Oberdörster, 2000; Schmid and Stoeger, 2016). The LDSA concentration is consequently a highly relevant metric in 
terms of health effects. A comparison of CADR for the different metrics is performed.

\section{METHODS}

\section{Setup in the Office}

The measurements were conducted in a furnished office room with a floor area of approximately $28 \mathrm{~m}^{2}$ and a volume of approximately $70 \mathrm{~m}^{3}$ (see Fig. 1). The furniture included two large book shelves, three desks, a variety of books and documents, and two computers. All measurements were conducted while the room was in use with at least one of the computers switched on. The room neither featured any forced ventilation nor any fresh air supply system, except for windows that can be opened. Consequently, when windows and the door were closed, fresh air was mainly provided by the infiltration from cracks around windows and doors.

The room is located in the main building of the Institute of Energy and Environmental Technology (IUTA) e. V. situated in an industrial area highly frequented by diesel trucks and is surrounded by the logistic centre of the largest European inland harbour (Duisburg, Germany). The outdoor air is consequently dominated by traffic exhaust. Therefore, the particle concentration inside the room could be increased deliberately by opening a window. The window remained open until approximately 5 minutes before starting the air cleaning device, when all windows and doors of the office were closed to temporise until roughly homogeneous spatial distribution of aerosol within the room might be reached.

The cleaning process was initiated using a portable air cleaner (AC4076; Philips) equipped with a highly efficient fibrous filter (AC4144; Philips). The filter used in this device is an electret filter, i.e., the filter fibres are electrically charged to enhance the filtration efficiency, whereas the particles are not actively charged at the inlet, e.g., by an ionizer. However, the charge on the fibres is typically lost during filter operation, resulting in reduced filtration efficiency. Therefore, besides new filters, discharged filters were used in the air cleaning device to mimic operation of the air cleaner with aged filters. By immersing an electret filter into isopropyl alcohol (IPA), the filter can be effectively discharged (Tang et al., 2018). Further details concerning aging methods can be found in Schumacher et al. (2018) and Finger et al. (2015). The settings of the cleaning device were kept constant during all measurements (performance level 3 out of 4 ) whilst the position of the air cleaner was varied (see Fig. 1) to detect possible effects on the local cleaning efficacy. In order to simulate realistic scenarios, positions were chosen according to convenience of the persons working in the room rather than with a view to optimal performance. Whereas in Position 1, 2 and 3 the air cleaner was freely drawing and releasing air, it was deliberately placed underneath a desk in Position 4 in order to mimic a rather unfavourable positioning.

In addition to concentration decay curves occurring due to the air cleaner operation, a natural decay curve was recorded while the air cleaner was switched off to separate this natural decay from the effect of the air cleaner. Based on the local decay rates with active and inactive air cleaner, the flow rate of clean air delivered to this location can be determined following the procedure described in GB/T 18801-2015 (compare Eq. (2)), using a chamber volume of $70 \mathrm{~m}^{3}$. The thereby determined values can be considered as local CADR within the office. According to GB/T 18801-2015, regression coefficients $R^{2}$ exceeding 0.98 are required to calculate CADR values. However such high correlations were not achieved in the office. However, $\mathrm{R}^{2}$ exceeded 0.9 during all experiments, showing a moderate to good correlation of the fitted and the measured data.

\section{Instrumentation Used in the Office}

The particle size distribution of the ambient aerosol was characterised by a Scanning Mobility Particle Sizer (SMPS;

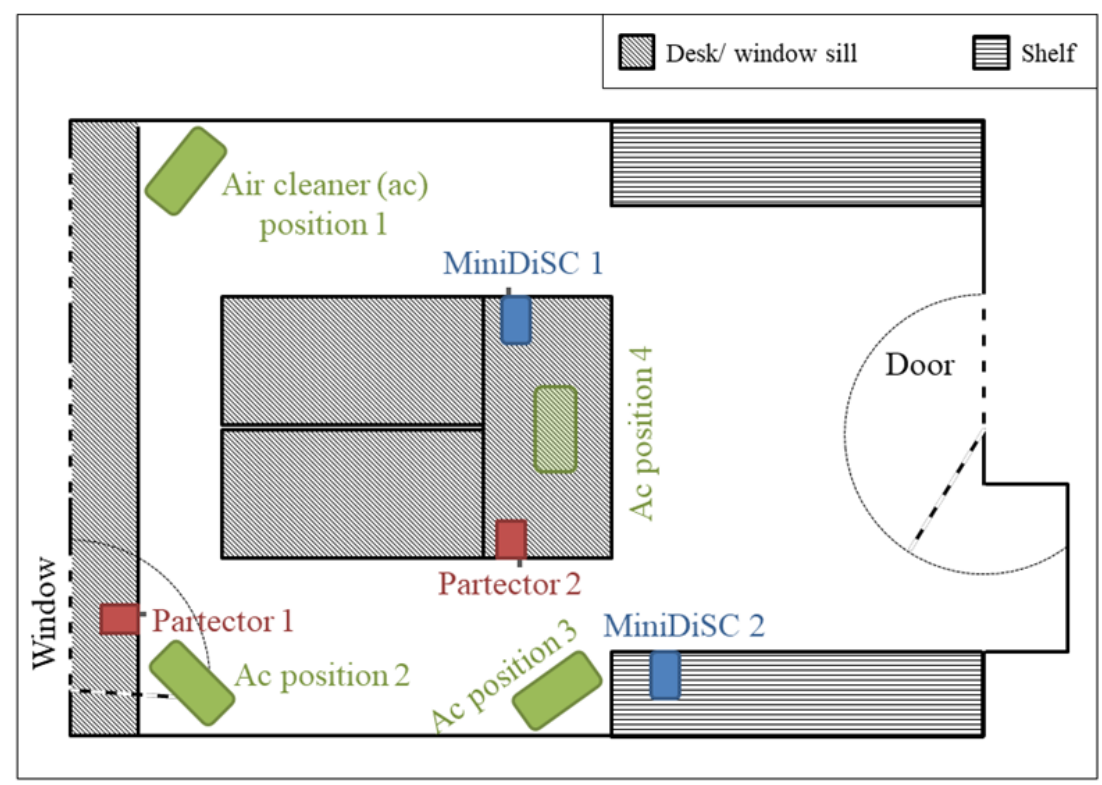

Fig. 1. Experimental setup within the office. 
sample flow $=0.3 \mathrm{~L} \mathrm{~min}^{-1}$, Model 3080; TSI) operated with a long differential mobility analyser (DMA; Model 3081; TSI) with a size resolution of 64 size channels per decade and an ultrafine water-based condensation particle counter (UWCPC; Model 3786; TSI) as well as by an optical particle counter with 16 size channels per decade (OPC; sample flow $=1 \mathrm{~L} \mathrm{~min}^{-1}$, Model 3330; TSI).

The LDSA concentration decay curves were measured by two different measurement devices: The Miniature Diffusion Size Classifier miniDiSC (Fierz et al., 2011) and the nanoparticle dosimeter partector by naneos (Fierz et $a l ., 2014)$. Two devices of each type were situated at fixed sites within the room and are denominated in Fig. 1 as "miniDiSC $1 \&$ 2" and "partector $1 \& 2$." Both instruments operate via diffusion charging and have been previously shown to deliver very repeatable results and to be around $\pm 30 \%$ accurate in determining the absolute concentrations (e.g., Todea et al., 2015; Asbach et al., 2017; Todea et al., 2017). We note that the accuracy for the determination of decay rates and thus CADR values is considerably higher than $\pm 30 \%$ since the appliances show an almost linear response over a wide concentration range. They were chosen due to their small size and rather silent operation as well as due to yielding a health-relevant metric. However, this is a deflection from GB/T 18801-2015, which prescribes using the total number concentration in the size range from 0.3 to $10 \mu \mathrm{m}$ for CADR determination.

\section{Setup for the Standardized Chamber Tests}

Prior to and after the measurements in the office, the CADR values of the applied filter/air cleaner combination were measured according to GB/T 18801-2015 in a standardized $30 \mathrm{~m}^{3}$ test chamber. Measurements were conducted using an OPC with 32 size channels per decade (sample flow $=5 \mathrm{~L} \mathrm{~min}^{-1}$, welas digital 2000 with aerosol sensor welas 2100; Palas) and, beyond the requirements according to GB/T 18801-2015, a Fast Mobility Particle Sizer with 16 size channels per decade (FMPS; sample flow $=10 \mathrm{~L} \mathrm{~min}^{-1}$, Model 3091; TSI) was used to take account of smaller particles. The results were on the one hand evaluated according to the standard for the particle number concentrations of particles $>0.3 \mu \mathrm{m}$ and on the other hand for LDSA concentrations. Assuming the particles to be spheres and considering the measured electrical mobility diameter (FMPS) and optical diameter (OPC) as the geometric particle diameter, respectively, LDSA concentrations were calculated by using the alveolar lung deposition curve according to a model by the International Commission for Radiological Protection (ICRP, 1994) for a reference worker (Fissan et al., 2007). Since both the LDSA concentration and the filter efficiency are particle size dependent, CADR values are different for number and LDSA concentration, even for the same test aerosol.

\section{RESULTS}

\section{Characterisation of the Test Aerosol}

As mentioned before, ambient air was used as target aerosol in the office room to simulate an authentic scenario. Due to heavy duty traffic in the vicinity, the ambient aerosol is expected to mainly comprise soot particles from diesel exhaust and other traffic related particles. For the test chamber experiments, a cigarette smoke aerosol was used in accordance with GB/T 18801-2015. Size distributions of both aerosols are shown in Fig. 2, revealing significant differences. This is inter alia reflected by the different mode values being at approximately $20 \mathrm{~nm}$ and $100 \mathrm{~nm}$ for the ambient aerosol and cigarette smoke aerosol, respectively.

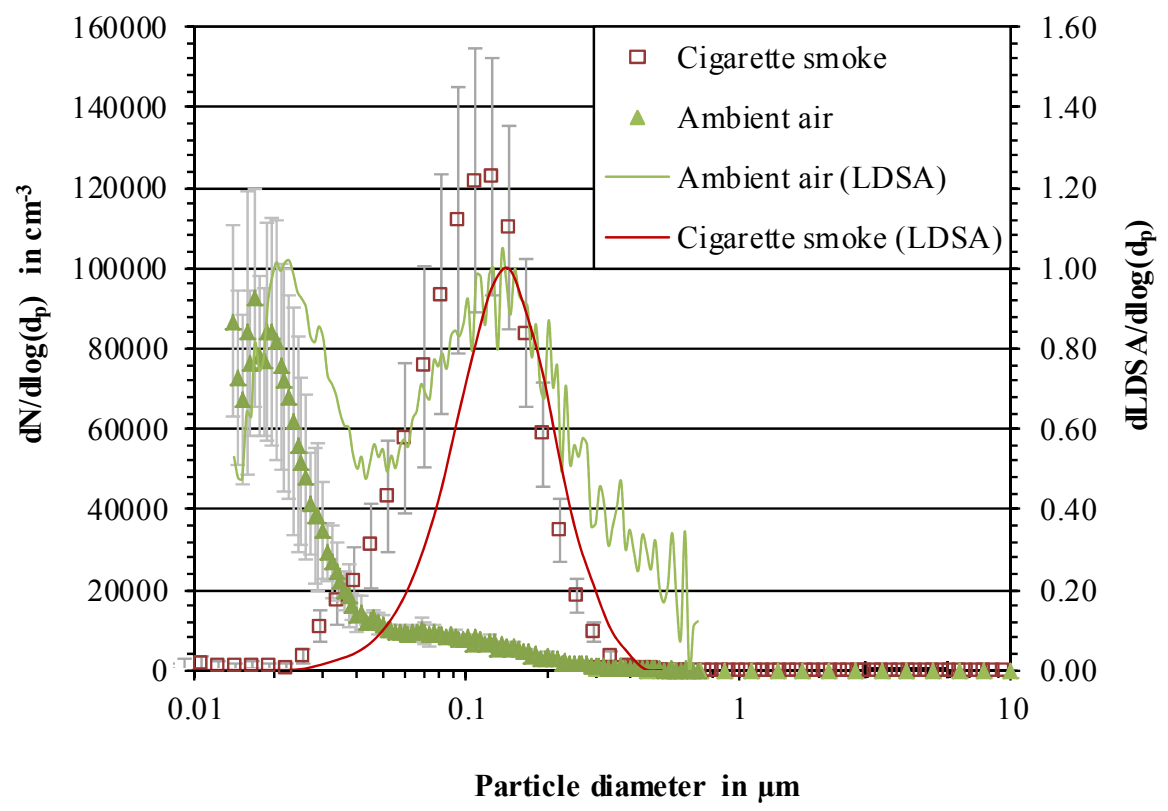

Fig. 2. Number size distribution of target aerosols: Ambient air in the office $(n=2)$ and cigarette smoke in the test chamber according to GB/T 18801-2015 $(\mathrm{n}=11)$ as well as duplicates of each size distribution weighted by alveolar deposition efficiencies (indicated by supplement $[L D S A]$ ). 
The ambient aerosol shows a small secondary mode at approximately the same size as the cigarette smoke, which presumably originates from the agglomeration of traffic generated primary particles. This bimodal size distribution of ambient particles as well as the congruence of the second mode with that of the cigarette smoke is even more pronounced when LDSA values are taken into account. In comparison to the number size distributions a slight shift of the LDSA size distributions to larger particle diameters can be observed.

\section{Comparison of CADR Based on Different Metrics}

To take a possible influence of applying different metrics for determination of the CADR values into account, they were evaluated for the measurements in the test chamber based on the number as well as on the LDSA concentration. The results are shown in Fig. 3, revealing almost similar values, although CADR based on LDSA concentrations is slightly lower compared to the values determined in accordance to the standard (GB/T 18801-2015).

\section{Spatial Variation of the LDSA Reduction}

As shown in Fig. 4, the relative decay of the LDSA concentration was almost identical at all sites where the four measurement devices were placed (compare Fig. 1), hinting towards a very homogeneous distribution of the cleaned air within the room. However, especially within the first minutes of air cleaning activity slight differences could be observed when the air cleaner was situated at Position 3 and 4. This trend is also confirmed by the mean CADR values visualized in Fig. 5: When the scatter is taken into account, for the new filters, no significant differences between the different measurement sites are observed. The only exceptions are the values measured with miniDiSC 1 when the air cleaner is situated at Position 3. This might be caused by turbulences or air recirculation produced by the air cleaning device in this position leading to higher inhomogeneity of the aerosol distribution throughout the office room. However, this trend could not be confirmed during the experiments using aged filters and thus further investigations are necessary to confirm this hypothesis.

Concerning the tests with aged filters, relative differences between the measurement sites within the office room are comparable to those of the new filters. Nevertheless, these results are more difficult to generalize since each measurement constellation was only tried once.

\section{Influence of the Position of the Air Cleaner}

For the sake of clarity as well as due to almost similar decay curves at all tested positions in the office, shown in Fig. 3, the results reported in the following are arithmetic means based on measurement data of all measurement devices (two miniDiSC and two partector devices, compare Fig. 3). An overview of all measurements and their results is given in Table 1.

As shown in Fig. 6, with respect to the determined CADR values almost no deviations between the different sites can be observed. When focussing on new filters, lowest mean CADR values were detected for Position $4\left(114 \mathrm{~m}^{3} \mathrm{~h}^{-1}\right)$. This is not very surprising, since Position 4 was located underneath a desk (see Fig. 1) and thus the counter top was likely acting as a flow obstacle, preventing efficient intake of the room air and homogeneous distribution of the clean air output. When taking the range indicated by error bars in Fig. 6 into account, the only significant difference in

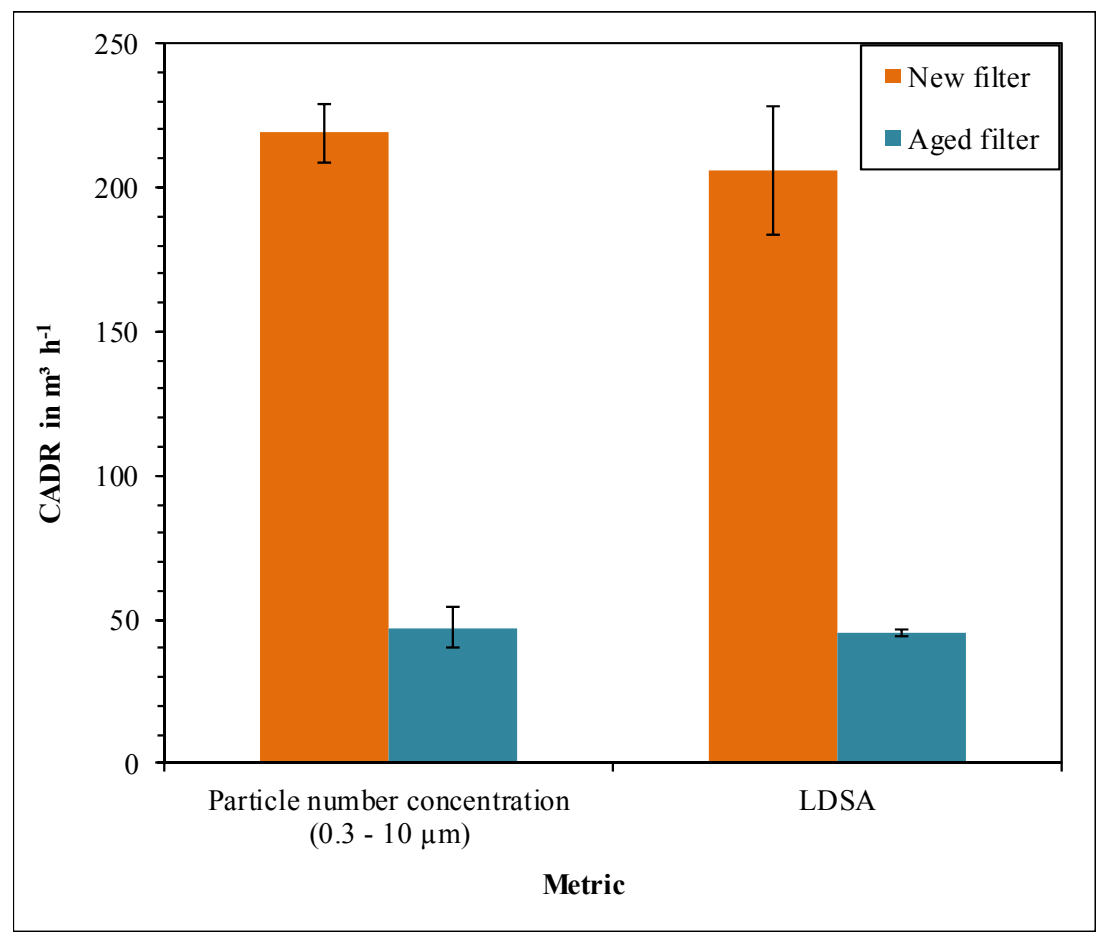

Fig. 3. Mean CADR (bars) with scatter (error bars) based on two different metrics for new and aged filters, $n=3$, respectively. 


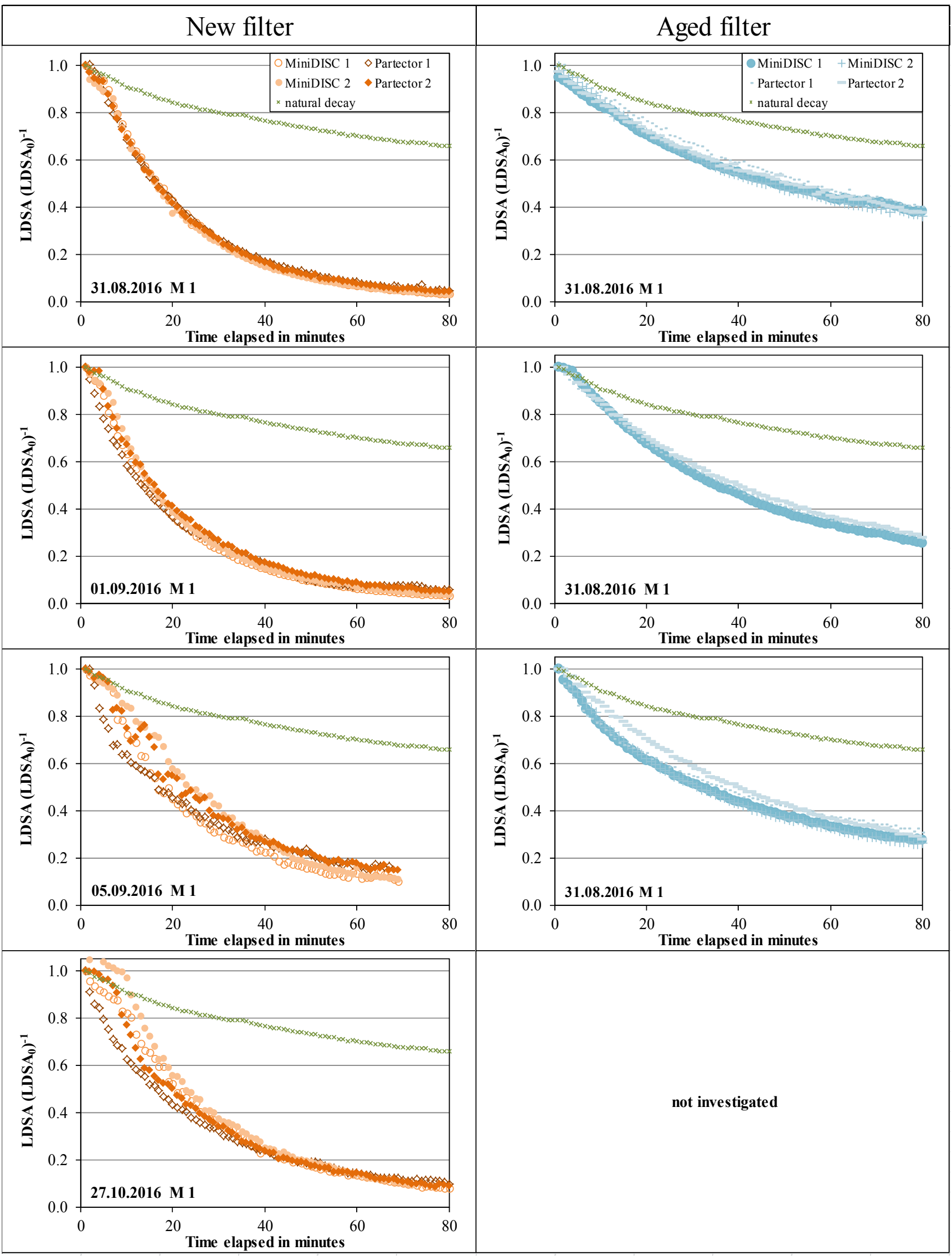

Fig. 4. Relative decay of the LDSA concentrations at different sites within the room for new and aged filters (one exemplary measurement for each position of the air cleaner). 


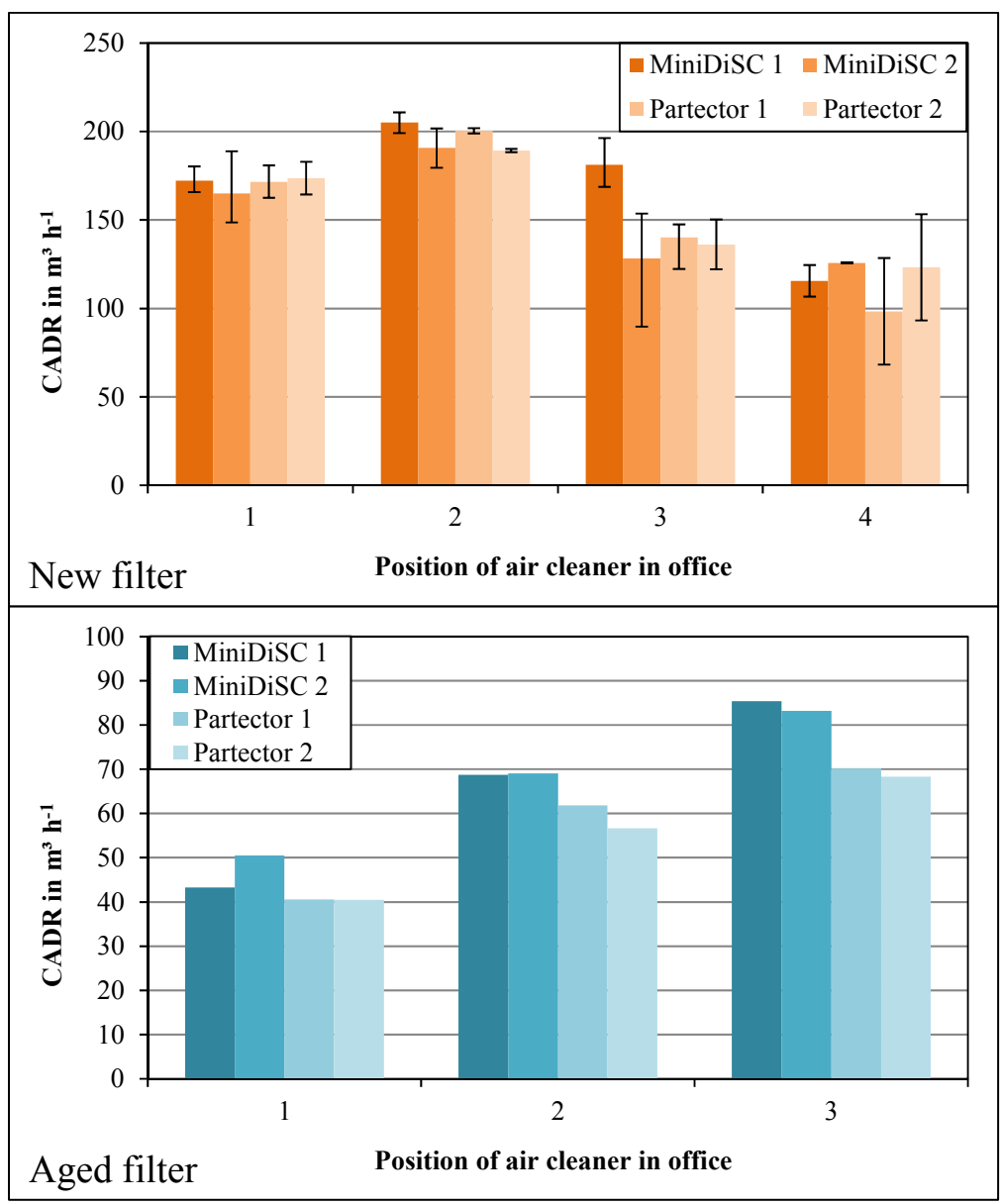

Fig. 5. Mean CADR (bars) with scatter (error bars) calculated based on LDSA concentration at different sites within the room for each position of the air cleaner.

CADR can be observed between Position 4 and Position 2, since at the latter mean CADR value of $196 \mathrm{~m}^{3} \mathrm{~h}^{-1}$ were detected.

CADR values for air cleaners equipped with artificially aged filters were in general significantly lower than for those with new filters (see Table 1), which is in line with the findings of Finger et al. (2015) and Schumacher et al. (2018), who observed similar effects during measurements conducted in the test chamber. This is due to the fact that electret filters have been used that can have significantly lower filtration efficiency in the discharged state (e.g., Kerner et al., 2018). No identical trend could be observed between new and aged filters concerning the ranking of CADR values for the different scenarios: Maximum mean CADR value was determined for Position 2 for the new filter with decreasing CADR at Position 1 followed by Position 3, whilst for the aged filter rising CADR values from Position 1 to Position 3 were observed (see Fig. 6).

\section{Comparison of Office and Test Chamber Results}

Compared to data from the test chamber (depicted in Fig. 6), for the air cleaning device equipped with new filters, lower CADR values were observed in the office. Although there is substantial scatter between the individual positions, the CADR averaged over Positions 1 to 3 in the office room was significantly lower than in the test chamber. However, a reversed trend was detected for aged filters. Additionally, the discrepancies between new and aged filters seem to be less pronounced within the office than in standardized measurements. Especially, only slightly reduced CADR values were observed at Position 3 when an aged filter was applied instead of a new one in the office. This might also be a result of higher variation in concentrations due to possible turbulences occurring in this air cleaner position, which is already mentioned above.

Furthermore, it should be kept in mind that only a single measurement was conducted at each position within the office room for the aged filter, whereas for the new filter at minimum a number of two measurements was achieved (Table 1). Generally, scattering in the office room is enhanced compared to the values measured in the test chamber.

\section{DISCUSSION}

\section{Possible Reasons for Lower CADR in Office Compared to Test Chamber Results}

Test Aerosol Size Distribution

The different size distributions of the aerosols during chamber tests and office measurements are likely the main reason for the lower CADR values determined in the office 


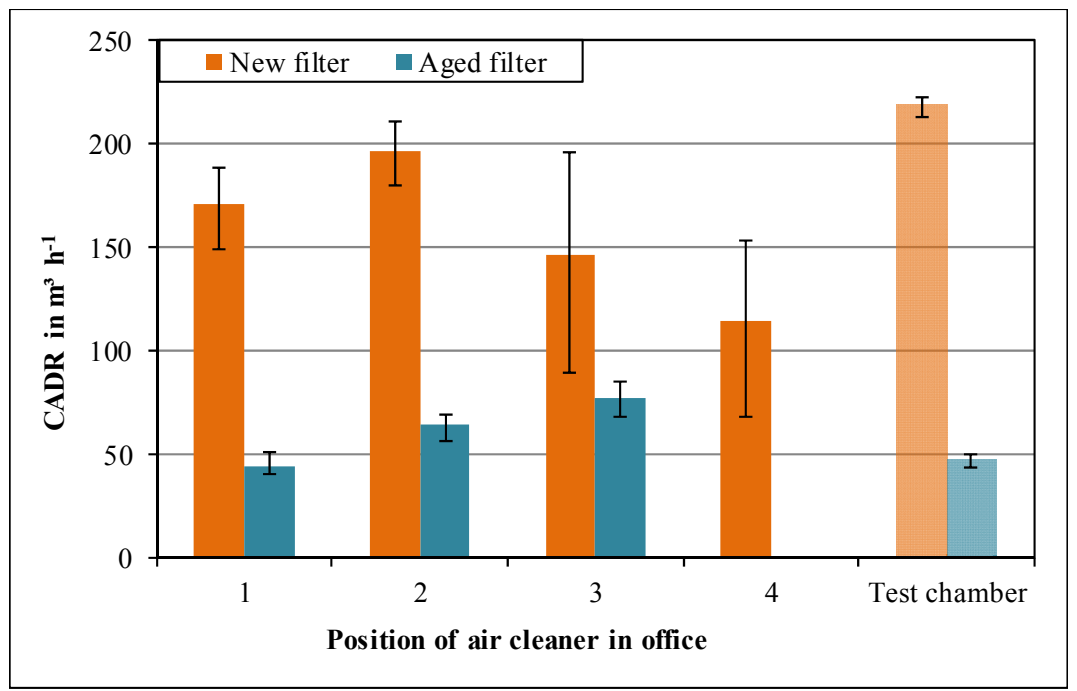

Fig. 6. Mean CADR (bars) with scatter (error bars) based on the LDSA concentration calculated from miniDiSC 1 and FMPS data for measurements conducted in the office and in the test chamber, respectively.

Table 1. Operating conditions and test results determined in the office (arithmetic mean of data from all measurement devices).

\begin{tabular}{llllll}
\hline Measurement & Position of air cleaner & Filter & $\mathrm{k}_{\mathrm{e}}$ in $\min ^{-1}$ & $\mathrm{R}^{2}$ & CADR in $\mathrm{m}^{3} \mathrm{~h}^{-1}$ \\
\hline M new 1 & 1 & new & 0.0463 & 0.98 & 172 \\
M new 2 & 1 & new & 0.0445 & 0.97 & 165 \\
M new 3 & 1 & new & 0.0489 & 0.99 & 183 \\
M new 4 & 1 & new & 0.0439 & 0.98 & 162 \\
M new 5 & 2 & new & 0.0530 & 0.99 & 200 \\
M new 6 & 2 & new & 0.0511 & 0.99 & 192 \\
M new 7 & 3 & new & 0.0367 & 0.95 & 132 \\
M new 8 & 3 & new & 0.0392 & 0.97 & 142 \\
M new 9 & 3 & new & 0.0417 & 0.98 & 153 \\
M new 10 & 3 & new & 0.0430 & 0.99 & 158 \\
M new 11 & 4 & new & 0.0287 & 0.96 & 98 \\
M new 12 & 4 & new & 0.0375 & 0.98 & 135 \\
M aged 1 & 1 & aged with isopropanol & 0.0157 & 0.99 & 44 \\
M aged 2 & 2 & aged with isopropanol & 0.0205 & 0.99 & 64 \\
M aged 2 & 3 & aged with isopropanol & 0.0236 & 0.96 & 77 \\
\hline
\end{tabular}

room compared to the CADR according to GB/T 188012015. As shown before, the mode of ambient aerosol used in the office was around $20 \mathrm{~nm}$ with a size distribution resembling those detected by other authors near major roads (e.g., Longley et al., 2003) whereas the mode of the cigarette aerosol was detected at approximately $100 \mathrm{~nm}$. Schumacher et al. (2018) previously investigated cleaning efficiencies of comparable portable air cleaners for different particle sizes and identified a significant reduction of the CADR with decreasing particle size for new filters. In their case, for 30-nm-sized particles CADR was approximately $30 \%$ lower than for $100-\mathrm{nm}$-sized particles. The reason is that the indoor air cleaners under investigation were equipped with electret filters. Since the probability of airborne particles to be charged decreases with decreasing particle size, the electrostatic enhancement of the filtration efficiency in electret filters is reduced for smaller particles. The same effect is expected here to cause the differences between the office room and test chamber measurements. However, a particle-size dependent study could not be conducted here since the portable devices provide only a size-integrated signal.

\section{Charge State of Test Aerosol}

Another reason for the differing CADR results may be possibly deviating charging states of the target aerosols. This influence factor cannot be ruled out, since studies conducted by Maricq (2006) and Jung and Kittelson (2005) found $60-80 \%$ of freshly emitted vehicle exhaust particles and diesel soot particles to be charged, whilst a slightly lower portion of fresh cigarette smoke particles exhibit charges (50-70\%; Borgerding and Klus, 2005, and references therein). However, in contrast to typical traffic emissions revealing a distinct number of particles to be in the accumulation mode, Fig. 2 indicates that the majority of target aerosol particles within the office were in the 
nucleation mode. Since traffic emissions in this mode were found to remain almost neutral (e.g., Jung and Kittelson, 2005; Maricq, 2006), the amount of charged particles of the ambient aerosol is assumed to underrun the values mentioned above. Additionally, it has to be considered that upon emission into air, due to interaction with air ions, particles will reach charge equilibrium close to a Boltzmann distribution, where the fraction of uncharged particles increases with decreasing particle size (Fuchs, 1963). However, assuming a typical concentration of positive and negative small ions of $200-2500 \mathrm{~cm}^{-3}$ (Hirsikko et al., 2011), this process could take up to several hours. Since the age of the ambient aerosol particles is not known, differences regarding the charging states of the target aerosols in the office and in the test chamber might have a share in differing CADR values.

\section{Initial Concentration of Test Aerosol}

Discrepancies in CADR determined in the office compared to the values identified following the standard might also be attributed to differing initial particle concentrations. Particle concentrations in the test chamber $(47,000 \pm$ 2000 particles $\mathrm{cm}^{-3}$ ) exceeded those realized in the office by a factor of about 2-10. However, the different initial concentrations should have no effect on the determined CADR, because the filter collection efficiency is independent of the particle concentration and all concentrations were well within the concentration ranges of the instrumentation used.

\section{Filter Aging during Tests in the Office Room}

Another reason for the differences between the results in the office and the test chamber might be that the filters could have been partially discharged or loaded with particles during the test measurements, yielding a different CADR for the office room measurements, which have been performed after the test chamber measurements. To investigate this effect, the standardized tests according to GB/T 18801-2015 have been repeated after the measurements in the office room and revealed almost identical CADR values as the initial measurements. Therefore, aging or loading effects during the tests can be excluded as a reason for the different CADR values.

\section{Influence of the Metrics}

No major differences in CADR values were detected when applying different metrics (LDSA and particle number concentration in the size range of $0.3-10 \mu \mathrm{m}$ ) during the test chamber experiments. However, the metric might be a relevant factor regarding the deviation of CADR determined in the office from that detected in the test chamber due to the different size distribution of the test aerosol, particularly when comparing the new and aged filters, which have distinctly different particle-sizedependent collection characteristics.

\section{Characteristics of the Office Compared to those of the Test Chamber}

Generally, standardized tests are conducted in tightly sealed test chambers without furnishing and with good air mixing. In contrast, infiltration through poorly sealed windows as well as through the gap underneath the door(s) might occur in an ordinary room, such as the office used in this study. Apart from this, in occupied rooms the flow and hence the pollutant dispersion can be much more complex. It may furthermore not be excluded that particles may have been emitted inside the office during the measurements, e.g., from motion of the person(s) inside the room or from the operation of computer(s). However, similar decay rates detected by the particle monitors at different positions in spite of missing active ventilation in the office signalize that this might be of minor relevance for our study.

\section{Homogeneity of the Clean Air Dispersion in the Office}

Although in the case of our study, positioning of the air cleaner within the office did not seem to have a strong influence on spatial distribution of the efficacy of the air cleaning, stronger effects in other office rooms or homes cannot be excluded, since studies by other authors are hinting towards differing directions. For instance, spatial variation of cleaning efficacy is of greater importance when one device is used to clean air within several connected rooms, as verified in a study by Novoselac and Siegel (2009). They positioned air cleaners in different rooms of a test house (residential building) and found the effective positioning of the cleaning device to result in a factor of up to 2.5 in overall particle removal. Additionally, the flow rate seems to be crucial in terms of spatial variation of cleaning efficiency, as shown by Jin et al. (2016). They conducted a simulation study investigating three different positions of stand-alone air cleaning devices within a furnished room by modelling particle concentrations of different size ranges and found particle concentration evolution to vary widely with the positioning of the air cleaner when the flow rate was low; however, the particle concentration would hardly be affected by the cleaner positioning when used with a high flow rate, due to the more uniform particle distribution. This is in line with findings by Quian et al. (2010) who detected effective air exchange rates and a good flow mixing within a simulated isolation ward containing virtual furniture when high air flow rates of approximately $530 \mathrm{~m}^{3} \mathrm{~h}^{-1}$ were realised by the HEPA air cleaner, whilst stagnant or dead zones were expected to exist at lower speeds.

\section{CONCLUSIONS}

The efficacy of a mobile air purifier used in a $70 \mathrm{~m}^{3}$ office room was investigated. The clean air delivery rate (CADR) was determined by using the health relevant lung deposited surface area (LDSA) concentration and compared to the data obtained from measurements conducted according to the Chinese standard GB/T 18801-2015. Whereas traffic-exhaust-dominated outdoor aerosol with a modal diameter of $\sim 20 \mathrm{~nm}$ was used as test aerosol in the office, cigarette smoke with a modal diameter of $\sim 100 \mathrm{~nm}$ was used in the GB/T 18801-2015 measurements.

The air purifier was placed in four different positions in 
the office, including one underneath a desk to mimic poor positioning. The LDSA concentration was then measured at four points in the room, and the local CADR was calculated from the concentration decay when the air purifier was running. The results revealed that the cleaned air was homogeneously dispersed throughout the entire office. The location of the free standing air purifier did not significantly influence the local CADR values. The mean CADR value when the air cleaner was placed underneath the desk was approximately $50 \%$ lower than that for the other three positions combined $\left(114 \mathrm{~m}^{3} \mathrm{~h}^{-1}\right.$ vs. $171 \mathrm{~m}^{3} \mathrm{~h}^{-1}$, respectively). Furthermore, due to the more realistic size distributions used in the office measurements, we found that the CADR values in the office room were below those measured in the standardized test chamber. Applying a different metric, LDSA instead of number concentration, however, had no major impact on the measured CADR. Overall, our results raise the question of whether using the test aerosol specified in the Chinese standard yields representative CADR values for air purifier use in nonsmoking households.

This study provides the first CADR data determined in an actual, used room taking into account different positions of the air cleaning device In our case, positioning the air cleaner immediately next to the window (which was the particle source) resulted in the highest cleaning efficiency throughout the room, whereas positioning it underneath the desk resulted in the lowest efficiency. However, further research-such as using test aerosols with more representative size distributions or determining particle size resolved CADR values as, for example, presented by Schumacher et al. (2018) - is needed to tackle potential factors that affect the CADR in real-world environments.

\section{ACKNOWLEDGMENTS}

The authors acknowledge Philips Consumer Lifestyle for providing the tested air cleaner and the corresponding filters.

\section{REFERENCES}

Anderson, J.O., Thundiyil, J.G. and Stolbach, A. (2012). Clearing the air: A review of the effects of particulate matter air pollution on human health. J. Med. Toxicol. 8: 166-175.

Asbach, C., Alexander, C., Clavaguera, S., Dahmann, D., Dozol, H., Faure, B., Fierz, M., Fontana, L., Iavicoli, I., Kaminski, H., MacCalman, L., Meyer-Plath, A., Simonow, B., van Tongeren, M. and Todea, A.M. (2017). Review of measurement techniques and methods for assessing personal exposure to airborne nanomaterials in workplaces. Sci. Total Environ. 603-604: 793-806.

Barn, P., Larson, T., Noullett, M., Kennedy, S., Copes, R. and Brauer, M (2008). Infiltration of forest fire and residential wood smoke: An evaluation of air cleaner effectiveness. J. Exposure Sci. Environ. Epidemiol. 18: 503-511.

Batterman, S., Godwin, C. and Jia, C. (2005). Long duration tests of room air filters in cigarette smokers' homes. Environ. Sci. Technol. 39: 7260-7268.

Borgerding, M. and Klus, H. (2005). Analysis of complex mixtures - Cigarette smoke. Exp. Toxicol. Pathol. 57: 43-73.

Bräuner, E.V., Forchhammer, L., Møller, P., Barregard, L., Gunnarsen, L., Afshari, A., Wåhlin, P., Glasius, M., Dragsted, L.O., Basu, S., Raaschou-Nielsen, O. and Loft, S (2008). Indoor particles affect vascular function in the aged: An air filtration-based intervention study. Am. J. Respir. Crit. Care. Med. 177: 419-25.

Chen, L., Jin, X., Yang, L., Du, X and Yang, Y. (2017). Particle transport characteristics in indoor environment with an air cleaner: The effect of nonuniform particle distributions. Build. Simul. 10: 123-133.

Chen, R., Zhao, A., Chen, H., Zhao, Z., Cai, J., Wang, C., Yang, C., Li, H., Xu, X., Ha, S., Kan, H. and Li, T. (2015). Cardiopulmonary benefits of reducing indoor particles of outdoor origin: a randomized, double-blind crossover trial of air purifiers. J. Am. Coll. Cardiol. 65: 2279-2287.

Dockery, D.W., Pope, C.A., Xu, X., Spengler, J.D., Ware, J.H., Fay, M.E., Ferris, B.G. and Speizer, F.E. (1993). An Association between Air Pollution and Mortality in Six U.S. Cities. N. Engl. J. Med. 329: 1753-1759.

Fierz, M., Houle, C., Steigmeier, P. and Burtscher, H. (2011). Design, calibration, and field performance of a miniature diffusion size classifier. Aerosol Sci. Technol. 45: 1-10.

Fierz, M., Meier, D., Steigmeier, P. and Burtscher, H. (2014). Aerosol measurement by induced currents. Aerosol Sci. Technol. 48: 350-357.

Finger, H., Schneiderwind, U. and Asbach, C. (2015). Bewertung mobiler Raumluftreinigungsgeräte. Gefahrstoffe - Reinhalt. Luft 75: 497-502.

Fisk, W.J., Faulkner, D., Palonen, J. and Seppanen, O. (2002). Performance and costs of particle air filtration technologies. Indoor Air 12: 223-234.

Fissan, H., Neumann, S., Trampe, A., Pui, D. and Shin, W.G. (2007). Rationale and principle of an instrument measuring lung deposited nanoparticle surface area. $J$. Nanopart. Res. 9: 53-59.

Fuchs, N. (1963). On the Stationary Charge Distribution on Aerosol Particles in Bipolar Ionic Atmosphere. Geofis. Pura Appl. 56: 185-193.

Guieysse, B., Hort, C., Platel, V., Munoz, R., Ondarts, M. and Revah, S. (2008). Biological treatment of indoor air for VOC removal: Potential and challenges. Biotechnol. $A d v .26: 398-410$.

Hanley, J.T., Ensor, D.S., Smith, D.D. and Sparks, L.E. (1994). Fractional aerosol filtration efficiency of in-duct ventilation air cleaners. Indoor Air 4: 169-178.

Hirsikko, A., Nieminen, T., Gagné, S., Lehtipalo, K., Manninen, H.E., Ehn, M., Hõrrak, U., Kerminen, V.-M., Laakso, L., McMurry, P.H., Mirme, A., Mirme, S., Petäjä, T., Tammet, H., Vakkari, V., Vana, M. and Kulmala, M. (2011). Atmospheric ions and nucleation: A review of observations. Atmos. Chem. Phys. 11: 767-798.

Huang, S.W. (1993). The effects of an air cleaner in the homes of children with perennial allergic rhinitis. Pediatr. Asthma Allergy Immunol. 7: 111-117. 
ICRP (1994). Human respiratory tract model for radiological protection. ICRP Publication 66. Ann. ICRP 24: 1-482.

Jenkins, P.L., Phillips, T.J., Mulberg, E.J. and Hui, S.P. (1992). Activity patterns of Californians: Use of and proximity to indoor pollutant sources. Atmos. Environ. 26: 2141-2148.

Jin, X., Yang, L., Du, X. and Yang, Y. (2016). Particle transport characteristics in indoor environment with an air cleaner. Indoor Built Environ. 25: 987-996.

Jung, H. and Kittelson, D.B. (2005). Measurement of electrical charge on diesel particles. Aerosol Sci. Technol. 39: 1129-1135.

Kerner, M., Schmidt, K., Hellmann, A., Schumacher, S., Pitz, M., Asbach, C., Ripperger, S. and Antonyuk, S. (2018). Numerical and experimental study of submicron aerosol deposition in electret microfiber nonwovens. $J$. Aerosol. Sci. 122: 32-44.

Leech, J.A., Nelson, W.C., Burnett, R.T., Aaron, S. and Raizenne, M.E. (2002). It's about time: a comparison of Canadian and American time-activity patterns. $J$. Exposure Anal. Environ. Epidemiol. 12: 427-432.

Longley, I.D., Gallagher, M.W., Dorsey, J.R., Flynn, M., Allan, J.D., Alfarra, M.R. and Inglis, D. (2003). A case study of aerosol $\left(4.6 \mathrm{~nm}<\mathrm{D}_{\mathrm{p}}<10 \mu \mathrm{m}\right)$ number and mass size distribution measurements in a busy street canyon in Manchester, UK. Atmos. Environ. 37: 1563-1571.

Ma, H., Shen, H., Shui, T., Li, Q. and Zhou, L. (2016). Experimental study on ultrafine particle removal performance of portable air cleaners with different filters in an office room. Int. J. Environ. Res. Publ. Health 13: 102.

Maricq, M.M. (2006). On the electrical charge of motor vehicle exhaust particles. J. Aerosol Sci. 37: 858-874.

Mo, J., Zhang, Y., Xu, Q., Lamson, J.J. and Zhao, R. (2009). Photocatalytic purification of volatile organic compounds in indoor air: A literature review. Atmos. Environ. 43: 2229-2246.

Nelson, P.R., Sears, S.B. and Heavner, D.L. (1993). Application of methods for evaluating air cleaner performance. Indoor Built Environ. 2: 111-117.

Noh, K.C. and Yook, S.J. (2016). Evaluation of clean air delivery rates and operating cost effectiveness for room air cleaner and ventilation system in a small lecture room. Energy Build. 119: 111-118.

Novoselac, A. and Siegel, J.A. (2009). Impact of placement of portable air cleaning devices in multizone residential environments. Build. Environ. 44: 2348-2356.

Oberdörster, G. (2000). Toxicology of ultrafine particles: In vivo studies. Philos. Trans. R. Soc. London, Ser. A 358: 2719-2740.

Polidori, A., Fine, P.M., White, V. and Kwon, P.S. (2013). Pilot study of high-performance air filtration for classroom applications. Indoor Air 23: 185-195.

Qian, H., Li, Y., Sun, H., Nielsen, P.V., Huang, X. and Zheng, X. (2010). Particle removal efficiency of the portable HEPA air cleaner in a simulated hospital ward. Build. Simul. 3: 215-224.

Schmid, O. and Stoeger, T. (2016). Surface area is the biologically most effective dose metric for acute nanoparticle toxicity in the lung. J. Aerosol Sci. 99: 133-143.

Schmid, S., Jecklin, M.C. and Zenobi, R. (2010). Degradation of volatile organic compounds in a nonthermal plasma air purifier. Chemosphere 79: 124-130.

Schumacher, S., Spiegelhoff, D., Schneiderwind, U., Finger, H. and Asbach, C. (2018). Performance of new and artificially aged electret filters in indoor air cleaners. Chem. Eng. Technol. 41: 27-34.

Sublett, J.L. (2011). Effectiveness of air filters and air cleaners in allergic respiratory diseases: A review of the recent literature. Curr. Allergy. Asthma. Rep. 11: 395-402.

Sultan, Z.M., Nilsson, G.J. and Magee, R.J. (2011). Removal of ultrafine particles in indoor air: Performance of various portable air cleaner technologies. $H V A C \& R$ Res. 17: 513-525.

Tang, M., Thompson, D., Chen, S.C., Liang, Y. and Pui, D.Y.H. (2018). Evaluation of different discharging methods on HVAC electret filter media. Build. Environ. 141: 206-214.

Todea, A.M., Beckmann, S., Kaminski, H. and Asbach, C. (2015). Accuracy of electrical aerosol sensors measuring lung deposited surface area. J. Aerosol Sci. 89: 96-109.

Todea, A.M., Beckmann, S., Kaminski, H., Bard, D., Bau, S., Clavaguera, S., Dahmann, D., Dozol, H., Dziurowitz, N., Elihn, K., Fierz, M., Lidén, G., Meyer-Plath, A., Monz, C., Neumann, V., Pelzer, J., Simonow, B.K., Thali, P., Tuinman, I., van der Vleuten, A., Vroomen, H. and Asbach, C. (2017). Inter-comparison of personal monitors for nanoparticles exposure at work places and in the environment. Sci. Total Environ. 605-606: 929-945.

Ward, M., Siegel, J.A. and Corsi, R.L. (2005). The effectiveness of stand alone air cleaners for shelter-inplace. Indoor Air 15: 127-134.

Zivin, J.G. and Neidell, M. (2018). Air pollution's hidden impacts. Science 359: 39-40.

Zuraimi, M.S., Nilsson, G.J. and Magee, R.J. (2011). Removing indoor particles using portable air cleaners: Implications for residential infection transmission. Build. Environ. 46: 2512-2519.

Received for review, January 17, 2019 Revised, May 14, 2019 Accepted, June 1, 2019 